\title{
An Assessment of the Causes of Low Performance in Music in Junior Secondary Schools in Enugu State: A Focus on Nsukka Local Government
}

\section{Area}

\author{
Dr Sunday N. Nnamani
}

\begin{abstract}
Department of Music Unit Fine, \& Applied Arts/Music, Federal University Ndufu-Alike, IKWO, PMB 1010, Abakaliki, Ebonyi State, Nigeria
\end{abstract}

\begin{abstract}
Music is the centre piece of life which gives human life a meaning and makes his existence worth its value. It determines man's interactional achievements and all that becomes of it and characterize the pattern of life and the extent of development in any society. This articles titled "An assessment of the causes of low performance in Music in J.S.S in Enugu State: A focus on Nsukka Local Government Area" discovered from the data presented that the students' are not interested in studying music, there is acute shortage of music teachers and musical instruments.

Others include low level of government's financial support and non-availability of qualified music teachers in the area.

The study adopted the empirical and historical methodologies before arriving at these results.

Five (5) secondary schools within the local government were studied, two (200) hundred questionnaires were distributed and a total of one (150) hundred fifty returned and analyzed using frequency distribution tables and percentages. Results were presented and the qualities of a good and effective music teacher presented.
\end{abstract}

Keywords- Music teacher, education, Enugu State, Musical instruments.

\section{INTRODUCTION}

Music had been one of the most important and expressive human activities in all cultures around the world for thousands of years. Music has been effectively coupled with words in chants and songs, and vocal music has been an important accompaniment to worship, work, recreation and a broad spectrum of other activities. A major advantage of music is that it can reflect and enhance human moods, emotions and activities, even though it cannot communicate specific ideas or thoughts without the help of words. But music, with and without words has shown itself to be capable of providing specific and direct comment on the people and cultures from which it came and it is this aspect of music and its history that is most enlightening to succeeding generations. The variety of styles and types of music that have evolved over the centuries is highly impressive as evidence of human ingenuity and imagination. Music occurs in every human society and it is therefore part of the culture of the society. It is thus possible to discuss music as it occurs in any given society or culture (Walter, 1996).

Formal education all over the world is the key to industrialization and economic growth. Music education on its part can contribute immensely in the current transformation agenda of the Federal Government of Nigeria through making her citizens to be self-reliant. Notably, the business of music education is the teaching and learning of music with the sole aim of developing in the students musical intelligence, competencies and appreciation. Music is not only an academic subject but is also a skill-oriented, glamorous and a technologicallyoriented subject.

Music education in Nigeria rests on a tri-level structure viz the traditional society, the popular music and the formal schools which include primary, post-primary and the tertiary level. The second level is the focus of this paper.

Historically formal music education started about the middle of the $19^{\text {th }}$ century according to (Okafor, 2002) "with the introduction of the Arabic schools and western schools". The principal aim was to produce musicians who could perform religious songs, chant, recite the Koran, teach Arabic music in line with Arabic culture and those who could teach church songs in choirs and for the schools' morning assemblies. It was on these plains and situations that music education began to develop. 
One of the most important things that has happened to education in Nigeria is the inclusion and recognition of music as a core subject in our schools. Apart from being a subject to be studied in our institutions, music is an excellent promoter of culture. In politics, it enhances campaigns that direct the voting patterns of the citizenry. This was confirmed by Mbanugo, (1999) when he said that "it can compel people to gladly sacrifice themselves to the larger humanity of the general society.... and remains always ready for slogan engineering to infect society with scientific and technological mentality".

\section{DEFINITION OF CONCEPTS}

Music: Many schools of thought including philosophers and scientists have thought of music from different perspectives. For instance Okpala and Anuforom (1988) defined it as "a universal language of the soul". It is universal because it has no language or age barrier and everyone both young and old understands, enjoys and appreciates good music. Different people sing, dance and play music written in languages other than theirs. Walter (1996) on his own part defined music as "sound arranged into pleasing or interesting patterns which forms an interesting part of many cultural and social activities. Like drama and dance, music is a performing art which plays a major role in other arts for example Opera, film and T.V. drama. In another vein it is seen as a "sacred art" or "a succession of organized sounds which the ear may interpret as pleasant, entertaining or enjoyable. The above definitions do not by any means exhaust other acceptable definitions of this subject.

For instance (Okpala, 1988), posited that;

Music is a social process by which human beings relate to one another through transmission of information, ideas, emotions, thoughts, norms, concepts and feelings among themselves. Music is the centre piece of life which gives human life a meaning and makes his existence worth its value...Music determines man's interaction achievements and all that becomes of it, and also dictates the tune of life as well as characterize the pattern of life and extent of development in any society.

\section{History of Enugu State}

Enugu is usually referred to as Enugu State to distinguish it from the city of Enugu which is a State, south-eastern part of Nigeria, created in 1991 from part of old Anambra state.
Its capital and largest city is Enugu from which the state derived its name. It was founded on $27^{\text {th }}$ August, 1991.

\section{Location and Population:}

Enugu state is located in the South-east geographical zone of Nigeria with a population of 3,267, 837 peoples according to record of the 2006 census (National Population 2006). Also the state has an estimated population of over 3.8 million people according to the census records of 2012 . It is the home of the Igbo of the southeastern and few Idoma/Igala people of Ette (Igboeze North) of Enugu state of Nigeria.

Meaning: Enugu means "Enugwu” Igbo meaning hill-top, capital of the former Eastern Region and the breakaway state of Biafra.

\section{Delimitation and Scope:}

Nsukka is the headquarters of Nsukka Local Government area, one of the 17 local government areas of Enugu state. The towns that share a common border with Nsukka are Eha-alumona, Edem, Alor-Uno, Opi, Orba, Ede-Obukpa, and Obima. It is a University town of the first indigenous University of Nigeria community referred to as U.N.N.

\section{Theoretical Framework}

The history of music education in Nigeria is based on oral tradition which was handed over from one generation to another. Music is one of the principal aspects of human culture and to the African and other peoples of the world; it remains a veritable way of life in situations of joy or sadness.

As for education, it is designed to equip the individual not only to earn a living but also for life through the encouragement of socially desirable knowledge, attitudes and skills. But everyone as a member of the world family must be educated to some extent that he will be aware of the goings-on in other parts of the world. It is on this respect that Donne (2016) said that;

No man is an island, entire of itself. Everyman is a piece of the continent a part of the main; if a clod be washed away by...this meditative prose conveys the essence of the human place in the world past and present. Everyman's death diminishes me. And therefore never send to know for whom the bell tolls.

To that extent therefore, music and expressions and it agrees with the views of the conference of churches meeting in Oxford (1937) which said;

Education is the process by which the community seeks to open its life to all the individuals within it to enable them to take their part in it. It attempts to pass on to them its culture, including the standards 
by which it would have them live. Where that culture is regarded as final, the attempts it made to impose it on the younger minds. Where it is viewed as a stage in development, that younger minds are trained both to receive it and to criticize and improve upon it.

Formal Music Education in Nigeria-The Place of University of Nigeria Nsukka.

Formal music education started with some teacher training colleges and secondary schools which enlarged their curricular to add lessons in the rudiments of music to singing and concert presentations.

The University of Nigeria Nsukka, (UNN), the first autonomous University in Nigeria, established the first college of music in Africa. It was a great step towards the dignity of music and the musician. One of the pioneer advanced teacher training colleges Alvan Ikoku Federal College of Education Owerri, also introduced music in its curriculum and began to produce music teachers/trainers for secondary schools and teacher training colleges.

Nevertheless, the common problems of the pioneering days were that the students were not as well equipped as was desirable, had limited out-of-school experience and that their grasp of the subject was weak. The University of Nigeria therefore organized concerts and seminars to expose their students to a bigger flood of musical currents. Not only students took part in the series of trainings but also the nearby choirmasters of churches and music teachers and practitioners. They also widened their musical horizon through these means. Even the students who were in nonmusic disciplines were exposed to organized music as part of their general studies curriculum. Furthermore, a diploma programme in music education half conservatory and half academic was introduced to train practicing musicians and music educators, leaving the degree programme for the academically minded and the potential trainers of trainers (Okafor, 2005).

For the University of Nigeria, Nsukka, its primary objectives of music education were;

a. To develop musicianship in the student

b. To produce teachers of music for the secondary level of education in Nigeria.

\section{J. S. S Music Curriculum}

The National Policy on Education (2004) recommended that the cultural and creative Arts should be taught as an integrated Arts Programme as it is practiced in our tradition and not to be compartmentalized into separate areas. But, the CCA curriculum for junior secondary school does not convey the idea of integration as do social studies or integrated science for the same level. The curriculum has been in use since 1985 and from the onset, the teachers were not given the orientation on how the content should be taught. The only exceptions are the National Teachers' Institute (NTI) Kaduna with centres across the country, a few colleges of Primary Education and Departments of Primary Education Studies (PES) of a few colleges established for the training of teachers for primary and junior secondary school levels.

The result is that music teachers teach music while Fine Art teachers teach fine arts. Dance as a subject is non-existent in the school system while drama on its own constitutes an integral part of English Literature. This is constituting a big problem especially in the junior secondary school basic arts examination. Here the objective and theory questions are derived from three areas only namely, Music, Arts and Drama with the ration of about 7:2:1 respectively. Something has to be done to remedy the situation if the aim of the integration is to be achieved.

Confirming the above therefore, Ekwueme (2002) said, "The Creative Arts curriculum for the Junior Secondary School is a document that contains sections for Fine Arts, Music and Drama while Dance is not included. Continuing she said that the following observations were noted.

1. The word "cultural" is omitted in the title.

2. The non-inclusion of a philosophy, rationale goals and general objectives explains the vagueness, lack of direction and inconsistencies in the curriculum. There is no evidence of continuity from the primary school cultural and creative Arts curriculum.

3. The Arts, like other subjects at the J.S.S. level are supposed to be integrated but rather, each subject area has its own separate syllabus.

4. For J.S.S 3 certificate Examination, there are separate question papers for music and Fine Arts. The questions for music are based on Grade 5 of the Associated Board of Royal Society of Music (ABRSM) London and not on the Nigerian music syllabus.

5. The creative Arts curricular are unsatisfactory as it is obvious that they were designed by individuals who did not understand the basic concept of an integrated curriculum.

\section{METHODOLOGY}

The researcher adopted the empirical and historical research methodologies in finding out the causes of low performances of music in Junior secondary schools in 
Enugu State with particular reference to Nsukka Local Government Area.

\section{Statement of the Problem:}

As earlier stated in the theoretical framework, the University of Nigeria Nsukka occupies a vantage position in the development of music education in Nigeria. This however is supposed to be reflected among the secondary schools around especially in Nsukka Local Government Area. The expectation is that students admitted in the neighboring secondary schools in Nsukka should develop keen interest in the study of music in view of the prominent role that music plays in the life of the individual and the society at large.

Yet inspite of all these expectations very few students in the school that offer music at the Junior secondary level get interested not to talk of offering it at the senior secondary level.

\section{Purpose of the Study}

The purpose of this study is to assess the causes of low performance in J.S.S music in Nsukka Local Government area. Specifically, the study will find out:

1. Why the students' interest in music are at a low ebb.

2. The causes of shortage of music teachers in the area.

3. The availability of musical instruments in the schools studied.

4. The level of government/local government financial and material support and its effect

5. The qualifications and experiences of the available music teachers.

\section{Research Questions}

1. Do students show interest in the study of music generally?

2. Do you have adequate number of music teachers for the schools in your area?

Table.1: Distribution of Questionnaire

\begin{tabular}{|l|l|l|l|l|}
\hline S/N & Schools & $\begin{array}{l}\text { Representative } \\
\text { letter }\end{array}$ & $\begin{array}{l}\text { No of } \\
\text { questionnaire }\end{array}$ & $\begin{array}{l}\text { No } \\
\text { Questionnaires } \\
\text { collected }\end{array}$ \\
\hline 1. & Edem Community Sec. School Edem & A & 40 & 35 \\
\hline 2. & St Cyprians Girls Secondary School Nsukka & B & 45 & 25 \\
\hline 3. & St Catherine's Secondary School Nsukka & C & 35 & 20 \\
\hline 4. & Community Secondary School Nru & D & 40 & 35 \\
\hline 5. & Community Secondary School Ede-Oballa & E & 40 & 35 \\
\hline & Total & & $\mathbf{2 0 0}$ & $\mathbf{1 5 0}$ \\
\hline
\end{tabular}

A total of two hundred (200) questionnaires were distributed and one hundred fifty collected from the schools that offer music. They are few and the teachers helped in the distribution and collection of the questionnaires. 
The researcher stayed back to see that the questionnaires were returned.

Table.2: Students' Interest in Music

\begin{tabular}{|l|l|l|l|l|}
\hline School & Yes & \% & No & \% \\
\hline A & 10 & 16.75 & 25 & 71.4 \\
\hline B & 5 & 20 & 20 & 80 \\
\hline C & 5 & 33 & 15 & 75 \\
\hline D & 6 & 17.1 & 29 & 77.1 \\
\hline E & 8 & 22.8 & 27 & 82.8 \\
\hline
\end{tabular}

In table 2 above it was shown that ten respondents in school "A" indicated their interest to study music, 5 in school "B"; 5 in school "C", 6 in school "D" and only 8 in school "E". The results in the above table has shown that generally students are not interested in studying this subject. This may be attributed to peer group influence, societal rejection and lack of encouragement from their parents.

Table.3: Inadequate Number of Music Teachers

\begin{tabular}{|l|l|l|}
\hline School & No of Teachers & No of Music Teachers \\
\hline A & 80 & 2 \\
\hline B & 45 & 1 \\
\hline C & 60 & 1 \\
\hline D & 30 & 1 \\
\hline E & 65 & 1 \\
\hline Total & $\mathbf{2 8 0}$ & $\mathbf{6}$ \\
\hline
\end{tabular}

Table 3 above on the number of music teachers in the five school studied showed a lot of lop-sidedness on the side of music. It was seen in school "A" that they had only two music teachers while the other four managed to get one teacher respectively.

This is grossly inadequate and a very urgent step has to be taken to address this anomaly.

Table.4: Availability of Musical Instruments.

\begin{tabular}{|l|l|l|}
\hline School & No of Musical Instruments & Type \\
\hline A & 7 & Keyboard \\
\hline B & 1 & Keyboard \\
\hline C & 0 & - \\
\hline D & 0 & - \\
\hline E & 1 & Clappers \\
\hline
\end{tabular}

On the availability of musical instruments in these schools recorded in table 4 above. It showed that only schools " $A$ " and " $B$ " has one keyboard instrument each schools " $C$ " and " $D$ " had non while school " $E$ " has one set of clappers. This is grossly inadequate because music is a performing art that involves theory and practicals. Any attempt on the study of music without the provision of musical instruments whether local or foreign is an effort in futility. The school authorities should liaze with the education authorities to provide these teaching aids and instructional material which are essential for proper teaching and learning in our schools.

Table.5: Government's Financial Support

\begin{tabular}{|l|l|l|l|l|}
\hline Schools & Yes & \% & No & \% \\
\hline A & 10 & 16.75 & 25 & 71.4 \\
\hline B & 5 & 20 & 20 & 80 \\
\hline C & 2 & 5 & 18 & 90 \\
\hline D & 3 & 8.5 & 32 & 91.4 \\
\hline E & - & & - & - \\
\hline
\end{tabular}


The table above has shown that governments' provision in these areas are grossly inadequate. The importance of adequate funding in educational development cannot be overemphasized and no organization can carry out its functions effectively without adequate financial resources at its disposal. In Nigeria secondary education derives its major funds from the annual allocation to the education sector. Unfortunately allocation to the education sector has been consistently low, inspite of its strategic role in the training of manpower for the development of the economy. Data from the Central Bank of Nigeria (2010) revealed that between 2000 and 2010, allocation to the education sector by the federal government of Nigeria was not more than $14 \%$ which was lower, when compared with that of other countries such as Kenya, Botswana, Anaola and Sierra Leone. (UNDP, 2011)

Table.6: Quality of Music Teachers/Qualifications

\begin{tabular}{|l|l|l|l|l|l|l|}
\hline Schools & No of Music Teachers & TCII & NCE & BA & MA & Ph.D \\
\hline A & 2 & 1 & 1 & - & - & - \\
\hline B & 1 & - & 1 & - & - & - \\
\hline C & 1 & - & - & 1 & - & - \\
\hline D & 1 & - & 1 & - & - & - \\
\hline E & 1 & 1 & - & - & - & - \\
\hline & 6 & 2 & 3 & 1 & - & - \\
\hline
\end{tabular}

Table 6 has shown that school "A" had two music teachers one possessing a teacher's grade II, and the other the Nigeria certificate in Education. School "B" has one NCE teacher, school "D" has one also while only school " $C$ " has one teacher that possesses a Bachelors Degree in Music. It is a pathetic situation and the greatest problem is that only one teacher teachers J.S.S 1 - III with their various arms. The result is that a times the teacher merges the classes together resulting in ineffective teaching due to overcrowding of students.

\section{DISCUSSION OF FINDINGS}

The findings of the study has shown that the causes of low performance in music, in Enugu state schools especially at J.SS 1-3 are as a result of the identified problems in this study.

The students have high rejection of the subject as identified by $71.4 \%, 80 \%, 75 \%, 77.1 \%$ and $82.8 \%$ respondents for schools A $-\mathrm{E}$ respectively. For the number of music teachers, inadequate provision of musical equipments and lack of governments' financial support, the story is exactly the same. For the quality or standard of the available teachers, the story is the same.

Conclusively, the researcher has arrived at the conclusion that the causes of low performance of students in music is as a result of all these forces combined.

\section{RESULTS}

The results stated above are not a true reflection of the efforts of the founding fathers of the Department of Music, University of Nigeria Nsukka. It was expected that Nsukka
Town and its environs will be a reference point in terms of musical development in Nigeria. Nevertheless, the music teachers around the country should endeavour is improve musically in order to move the course to a greater height.

In the light of these developments, the researcher hereby recommends that a music teacher should possess the following qualities.

He must understand that choosing music education as a career makes him or her unique. He should rise above bias or discrimination as everyone knows that music is a subject in Nigerian education that has an obscure status especially since parents do not encourage their children to study it. Consequently, the role of music teacher is manifold, and he must:

- Be a musician;

- Be a performer;

- Possess good and warm personality;

- Be a guidance counselor;

- Be human and sympathetic;

- $\quad$ Love children and be friendly;

- Understand his pupils

- Inspire and encourage students to learn music

- Make music learning interesting and fun and at the same time impart knowledge, skills and values;

- Make students educated consumers and good amateurs of music.

It is generally advisable that for teachers to be productive and effective in the teaching of music, they must have good mastery of the subject matter, a good knowledge base, and competence in the practical/applied music, good level of 
musicianship and must be creative and resourceful.

(Ekwueme, 2010)

\section{REFERENCES}

[1] Conference of Churches: The Churches Survey Their Task. A Report Published in Oxford, 1937.

[2] Donne, J.A (2016). A Publication by J.D Donne in 1624. https://m.poemhunter.com/.../Retrieved 24th June, 2016

[3] Ekwueme, L.U. (2002). Music Education and Sociopolitical Issues in Nigeria. Keynote Address, Conference of Music Education in Nigeria (COMEN) FCE Okene, 7-10 August.

[4] Ekwueme, L.U. (2010). School Music Methods-A Handbook for Teachers Apex Books Limited: Lagos

[5] Mbanugo, C.E (1999). Towards a Philosophy of Music Education in Nigeria. Unizik Journal of Arts and Humanities, (i) 234-243

[6] National Policy on Education (2004) Federal republic of Nigeria, NERC: Lagos

[7] National Population Commission (2006) Report on Population Census.

[8] Okafor, R. C (2002). Music Education and Sociopolitical Issues in Nigeria. Lead Paper, Conference of Music Educator in Nigeria (COMEN) FCE Okene; 710 August

[9] Okafor, R.C (2005). Music in Nigerian Society. Enugu: New generation Books

[10] Okpala, A.A (1988). Perception: An Important Factor in Using Music for Effective Communication. Journal of Social Studies

[11] Okpala, A.A \& Anuforom, U: (1988). Fundamentals of Music. Owerri: Colon Concept Ltd

[12] United Nations Development Programme (2011) Human Development Programme Report. New York: U. S. A.

[13] Walter, K. (1996) "Music to Numazu" Collier's Encyclopedia Vol.17 Mauran S. Bahr, Bernard Johnson, Louise A. Bloomfield, editors (1996) New York. 